\title{
MMT and LDH organo-modification with surfactants tailored for PLA nanocomposites
}

\author{
S. Coiai ${ }^{1}$, F. Cicogna ${ }^{1}$, A. de Santi ${ }^{1}$, L. Pérez Amaro ${ }^{1}$, R. Spiniello ${ }^{1}$, F. Signori ${ }^{2}$, S. Fiori ${ }^{3}$, \\ W. Oberhauser ${ }^{4}$, E. Passaglia ${ }^{1 *}$ \\ ${ }^{1}$ Istituto di Chimica dei Composti OrganoMetallici (ICCOM) CNR SS Pisa, Area della Ricerca, via Moruzzi 1, 56124 Pisa, \\ Italy \\ ${ }^{2}$ Istituto per i Processi ChimicoFisici (IPCF) CNR SS Pisa, Area della Ricerca, via Moruzzi 1, 56124 Pisa, Italy \\ ${ }^{3}$ R\&D Department, Condensia Química S.A, C/La Cierva 8, 08184 Palau de Plegamans, Barcelona, Spain \\ ${ }^{4}$ Istituto di Chimica dei Composti OrganoMetallici (ICCOM) CNR,Via Madonna del Piano 10, 50019 Sesto Fiorentino, \\ Firenze, Italy
}

Received 9 August 2016; accepted in revised form 18 October 2016

\begin{abstract}
Low molecular weight polyesters were end-functionalized with ammonium and carboxylate salts and used in ionic exchange reactions with respectively cationic (MMT) and anionic (LDH) clays. The hybrid organic-inorganic substrates were structurally analysed to determine the ester oligomers' modification degree and their thermal behaviour owing to confinement effects. The dispersion of such hybrids in polylactic acid (PLA) matrix was performed and the ultimate structural, morphological and thermal properties of the collected nanocomposites were investigated and correlated to the tailored interfacial properties with the different inorganic substrates. While the composites with MMT proved to be stable under thermo-oxidative conditions, the samples obtained by dispersing the LDH hybrid suffered from poor final thermostability owing to molecular weights decrease. Deeper insights about the effect of the interactions at interface (polymer chain-surfactant and polymer chain- inorganic surface) evidenced that by promoting an intimate contact between PLA chains and LDH surface (through oligoester used as inorganic substrate modifier) a certain extent of PLA hydrolysis triggered by both surfactant and inorganic surface (LDH) occurred and cannot completely avoided.
\end{abstract}

Keywords: nanocomposites, MMT, LDH, PLA, tailor-made polymer

\section{Introduction}

It is well known that the ultimate characteristics of polymer nanocomposites by dispersing $2 \mathrm{D}$ nanostructured fillers are depending and affected by interfacial interactions between macromolecules and inorganic surfaces [1]. Especially the chemistry of such kind of interactions plays a significant role in decreasing the enthalpy associated to the intercalation/exfoliation process and therefore the functionalities on both polymer chains and inorganic surface have to be specifically tailored to maximize interactions and optimize the final morphology $[2,3]$.
During the last decades, polylactic acid (PLA), a polymer derived from lactic acid, has become an emergent bio-based polymer since it can be obtained from renewable resources, it can be processed by injection/ blow moulding, it has high strength and modulus (comparable to those of polystyrene and polyethylene terephthalate), and it is recyclable and compostable [4]. However, PLA exhibits some drawbacks mainly related to its low heat distortion temperature, high gas and vapour permeability, and poor resistance to protracted processing operations; all these features have, for the moment, limited its applications particularly

${ }^{*}$ Corresponding author, e-mail: passaglia@pi.iccom.cnr.it (C) BME-PT 
in packaging uses. Reinforcement of PLA through the addition of macro or nano-scaled fillers has been successfully reported to provide nanocomposites for various applications $[5,6]$. With reference to layered inorganic systems both montmorillonite (MMT) and layered double hydroxides as hydrotalcite (LDH) have been used. In both cases the use of surfactants (ionic salts employed as organomodifiers) is necessary to enlarge the intergallery spacing and to make more lipophilic the filler surface aimed at favouring complete exfoliation and then morphologies suitable to reach the target features (mechanical improvements and/or barrier properties) [7-10].

Most of the work is based on the utilization of commercial organo-MMT and/or LDH, generally used for the preparation of nanocomposites with different polymers and not necessarily targeted in the structure to be analogous to (or compatible with) PLA. All the surfactants are chosen from among the ammonium salts or carboxylates containing long alkyl chains, aromatic moieties and more recently chemicals able to transfer special functional properties to PLA matrix (antioxidants, UV blockers, chromophores) [11, 12]. Quite good results were reached by dispersing the modified inorganic fillers in the PLA matrix with either solvent or melt mixing procedure in terms of morphological and barrier properties (particularly with MMT-based substrates), but the structural and the thermal stability of these systems is still a challenge $[10,13,14]$.

In this scenario the use of organo-modifiers having a chemical structure similar to that of PLA matrix, and, indeed, made by end-functionalized ester oligomers, was here proposed for the first time to modify sodium montmorillonite and $\mathrm{Mg}$ - $\mathrm{Al}$ layered double hydroxides.

In particular low molecular weight ammonium-terminated PLA (Figure 1a) was intercalated in sodium montmorillonite (Na-MMT, commercial sample);

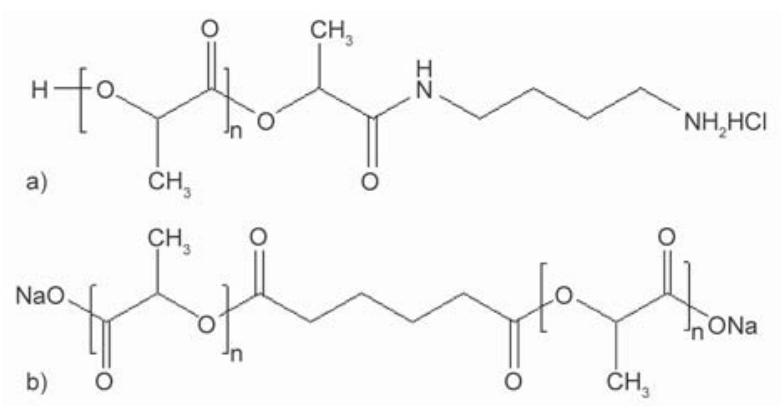

Figure 1. Structure of end-functionalized PLA oligomers: (a) PLA- $\mathrm{NH}_{3} \mathrm{Cl}$, (b) PLA-COONa similarly low molecular weight PLA (with a di-block structure, Figure 1b) terminated with sodium carboxylate was intercalated in nitrate hydrotalcite (LDH-NO ${ }_{3}$, previously synthetized from commercial hydrotalcite). In both cases the ion exchange procedure gave hybrid PLA-based compounds that, after careful structural and thermal characterization, were dispersed in the PLA matrix. The collected nanocomposites were analysed in terms of morphological and thermal features and the results compared by taking into account the chemical nature of the different inorganic fillers and modifier functionalities and their effects onto the final thermal stability.

\section{Experimental part}

\subsection{Materials}

Montmorillonite (MMT-Na, CEC (cationic exchange capacity) $=128 \mathrm{meq} / 100 \mathrm{~g}$, from technical sheet) produced by Laviosa Chimica Mineraria, (Italy) and Layered Double Hydroxide ( $\mathrm{LDH}-\mathrm{CO}_{3}$ ) produced by Sasol Germany GmbH (Germany) were used without any treatment as precursor for the ion exchange reaction to synthetize nanostructured hybrid materials. The oligomer of lactic acid, amino terminated (PLA$\mathrm{NH}_{3} \mathrm{Cl}$ ), synthetized according to ten Breteler et al. [15] was used for the modification of MMT-Na. Proton nuclear magnetic resonance, ${ }^{1} \mathrm{H}-\mathrm{NMR}\left(\mathrm{CDCl}_{3}\right)$ : 6.9, (bs, NH), $5.15\left(q, \mathrm{nH}, \mathrm{CHCH}_{3}\right), 4.38(q, 1 \mathrm{H}$, $\mathrm{CHCH}_{3}$ final unit), 3.0-3.4 ( $\left.m, 4 \mathrm{H}, \mathrm{CH}_{2} \mathrm{NH}\right), 1.55$ $\left(d, 3 \mathrm{nH}, \mathrm{CHCH}_{3}\right), 1.5\left(q, 4 \mathrm{H}, \mathrm{CH}_{2}\right)$. On the basis of these attributions (see also Figure 1a) $n+1=23$ and $\bar{M}_{\mathrm{n}}=1779$ Da were calculated.

The oligomer of lactic acid, carboxyl terminated (PLA-COONa) synthetized and supplied by Condensia Química S.A. (Spain) was used for the modification of LDH. ${ }^{1} \mathrm{H}-\mathrm{NMR}\left(\mathrm{D}_{2} \mathrm{O}\right): 4.22\left(q, \mathrm{nH}, \mathrm{CHCH}_{3}\right)$, $2.4\left(m, 4 \mathrm{H},-\mathrm{COCH}_{2} \mathrm{CH}_{2}-\right), 1.8-1.6(m, 4 \mathrm{H}$, $\left.-\mathrm{COCH}_{2} \mathrm{CH}_{2}-\right), 1.5-1.4\left(d, 3 \mathrm{nH}, \mathrm{CHCH}_{3}\right)$. On the basis of these attributions (see also Figure 1b) $2 n=7$ and $\bar{M}_{\mathrm{n}}=662 \mathrm{Da}$ were calculated

Poly(lactic acid) (PLA), Ingeo 2003D (96\% L-LA) characterized by $\bar{M}_{\mathrm{n}}=141 \mathrm{kDa}$ and $\bar{M}_{\mathrm{w}}=213 \mathrm{kDa}$ by Nature Works (USA), chloroform HPLC grade, methanol RPE and ethanol $96^{\circ}$ RPE by Carlo Erba (Italy) were used as received.

\subsection{Preparation of nanostructured hybrid materials}

The chemical modification of inorganic materials (MMT-Na and LDH-CO ${ }_{3}$ ) was done by ion-exchange 
reactions in the presence of their respective organic counterparts under controlled conditions.

\section{MMT-Na modification}

A three neck bottom flask of $100 \mathrm{~mL}$, having a refrigerator unit, was filled with $15 \mathrm{~mL}$ of MMT-Na suspension containing $3.2 \mathrm{wt} \%$ of inorganic substrate; after diluting $9 \mathrm{~mL}$ of deionized water $1 \mathrm{~g}$ of PLA$\mathrm{NH}_{3} \mathrm{Cl}$ (corresponding to a large excess with respect to $\mathrm{CEC}$ of MMT) was added. The suspension was then left stirring at $80^{\circ} \mathrm{C}$ for three hours and was afterwards filtered to recover the solid (grey powder) product which was washed with $20 \mathrm{~mL}$ of deionized water for three times. The residue $\left(\mathrm{MMT}-\mathrm{PLANH}_{3}\right)$ was further purified by washing twice with $20 \mathrm{~mL}$ of acetonitrile and $20 \mathrm{~mL}$ of acetone. Then the resulting powder was dried under vacuum until constant weight was reached. The organic content hybrid was $29 \mathrm{wt} \%$ wt as determined by TGA.

\section{$\mathrm{LDH}-\mathrm{CO}_{3}$ modification}

The commercial product was first converted into the nitrate form ( $\left.\mathrm{LDH}-\mathrm{NO}_{3}\right)$ according to the titration procedure reported by Muksing et al. [16]. The resulting product with a calculated anion-exchange capacity (AEC) of 385 meq of $\mathrm{NO}_{3} / 100 \mathrm{~g}$, was then subjected to the organic anionic exchange reaction: a three neck bottom flask of $100 \mathrm{~mL}$ was filled, under $\mathrm{N}_{2}$ flow, with $386 \mathrm{mg}$ di PLA-COONa and $10 \mathrm{~mL}$ of $\mathrm{CO}_{2}$-free deionized water. The $\mathrm{pH}$ of the solution was fixed at around 9 with weighted amount of $\mathrm{NaOH}$. Then, $100 \mathrm{mg}$ of $\mathrm{LDH}-\mathrm{NO}_{3}$ was added into the flask and the suspension was left under vigorous stirring in inert atmosphere for four days. Then, the white solid (LDH-PLACOO) was filtered and washed several time with $\mathrm{CO}_{2}$-free deionized water until $\mathrm{pH}$ 7. Finally the product was dried until constant weight by using a freeze-drying procedure for two days. The organic content hybrid was $25 \%$ wt as determined by TGA.

\subsection{Preparation of PLA based composites}

Two series of samples containing about 1 and $2 \mathrm{wt} \%$ of inorganic substrates were prepared by dispersing respectively MMT-PLANH ${ }_{3}$ and LDH-PLACOO in PLA matrix by using a solvent/suspension procedure. First the organo-modified and unmodified MMT and LDH (generally $10 \mathrm{mg}$ ) were put in a test tube with $5 \mathrm{~mL}$ of solvent mixtures; respectively ethanol/ chloroform 50/50 (v/v) and methanol/chloroform
30/70 (v/v). Then, the samples were submitted to ultrasound in order to destroy macro-aggregates and to obtain, as possible, delamination of the hybrid system in the liquid medium. As example of typical procedure, a sonication treatment (by Ney Ultrasonik 28X Degasser) was applied for $40 \mathrm{~min}$ at $T=40^{\circ} \mathrm{C}$.

A solution containing $1 \mathrm{~g}$ PLA resin dissolved in $25 \mathrm{~mL}$ of chloroform was put in a one-necked roundbottom flask of $250 \mathrm{~mL}$. Then, a right volume of the hybrid suspension, which was freshly dispersed by ultrasound, was added drop by drop into the PLA solution to collect sample composites containing 1 and $2 \mathrm{wt} \%$ of inorganic substrates. Afterwards the obtained composite was partially dried under reduced pressure by using a rotating evaporator at low rpm and finally dried until constant weight was reached.

Blank samples, in particular PLA treated in the same experimental conditions without inorganic substrate (named PLA_son), PLA treated with $2 \mathrm{wt} \%$ of unmodified MMT-Na and LDH- $\mathrm{CO}_{3}$ (named respectively PLA_MMT and PLA_LDH) and PLA treated with $1 \mathrm{wt} \%$ of PLA-COONa oligomer (named PLA_PLA-COONa) were prepared for comparison purpose.

The characterizations were performed by using composite films obtained by hot-pressing the sample with a press Carver 3851CE: $T=180^{\circ} \mathrm{C}, 3$ bars, $3 \mathrm{~min}$.

\subsection{Characterization}

XRD patters of hybrid systems and PLA based composites were recorded using a X'Pert Pro PANalytical $(\mathrm{Cu} \mathrm{K} \alpha, \lambda=1.541874 \AA$ ) (The Netherlands) equipped with a Ni filter of $0.02 \mathrm{~nm}$ and a fast detector PIXcel with an active range of $3.347^{\circ}$. The scanning interval in $2 \theta$ was from 1.5 to $30^{\circ}$ with a scanning range of 0.0131 and 207.5 seconds as acquisition time. Powders of the hybrid systems (MMT-PLANH ${ }_{3}$ and LDH-PLACOO) as well as their respective PLA films were analysed in the same experimental conditions, these latter after annealing overnight at $110^{\circ} \mathrm{C}$. The interlayer spacing between the clay layers was computed by applying the Bragg's law. Infrared spectra were recorded with a Fourier Transform Spectrometer PerkinElmer Spectrum 100 (Monza, Italy) over the wavenumber range of 450 $4000 \mathrm{~cm}^{-1}$. The spectra of hybrids as well as those of the ester oligomers were obtained by mixing the samples with potassium bromide ( $\mathrm{KBr} 99.4 \%$ spectroscopic grade purchased from Sigma-Aldrich) or by using ATR mode. 
Thermogravimetric analysis (TG) were performed with Seiko EXTAR 7200 TGA/DTG instrument (Woodland, CA), under air flow using $5-10 \mathrm{mg}$ of sample and heating from 30 until $700^{\circ} \mathrm{C}$ at $10^{\circ} \mathrm{C} / \mathrm{min}$ as scanning rate.

Differential scanning calorimetry (DSC) analyses were carried using a Perkin-Elmer DSC 4000 (Monza, Italy) instrument controlled by the software Pyris 9.0.2.0193 (5-10 mg of each samples) under nitrogen atmosphere. The instrument was calibrated with In $\left(T_{\mathrm{m}}=156.60^{\circ} \mathrm{C}\right.$ and $\left.\Delta H_{\mathrm{m}}=28.38 \mathrm{~J} / \mathrm{g}\right)$ and $\mathrm{Pb}$ $\left(T_{\mathrm{m}}=327.47^{\circ} \mathrm{C}\right.$ and $\left.\Delta H_{\mathrm{m}}=23.03 \mathrm{~J} / \mathrm{g}\right)$ as standards. The composites were analysed before and after annealing (performed at $110^{\circ} \mathrm{C}$ for $8 \mathrm{hs}$ ) and the crystallinity calculated using the Equation (1):

$\chi=X_{\mathrm{PLA}}{ }^{-1} \frac{\Delta H_{\mathrm{m}}+\Delta H_{\mathrm{cc}}}{\Delta H_{100 \% \mathrm{c}}} \cdot 100$

where $X_{\mathrm{PLA}}{ }^{-1}$ is the fraction of PLA, $\Delta H_{\mathrm{m}}$ is the melting enthalpy of the sample and $\Delta H_{\mathrm{cc}}$ enthalpy of cold crystallization. $\Delta H_{100 \%}$ is the melting enthalpy of a $100 \%$ crystalline PLA $(93.6 \mathrm{~J} / \mathrm{g}$ ) [17].

Determinations of oxidation induction time (OIt) were carried out using the software Pyris 9.0.2.0193 by DSC in OIT mode according to the testing procedure of ISO 11357-6-2008. Measurements were performed on disk specimens having a thickness ranging from 0.20 to $0.45 \mathrm{~mm}$ and weight around 5$10 \mathrm{mg}$. Samples were isothermally treated at $30^{\circ} \mathrm{C}$ under nitrogen flow $\left(50 \mathrm{~mL} \cdot \mathrm{min}^{-1}\right)$ for $5 \mathrm{~min}$, then they were heated from 30 to $230^{\circ} \mathrm{C}$ at $20^{\circ} \mathrm{C} / \mathrm{min}$ under nitrogen flow $\left(50 \mathrm{~mL} \cdot \mathrm{min}^{-1}\right)$. After maintaining in nitrogen for $5 \mathrm{~min}$ to attain thermal equilibrium, the gas was switched to oxygen flow $\left(50 \mathrm{~mL} \cdot \mathrm{min}^{-1}\right)$.

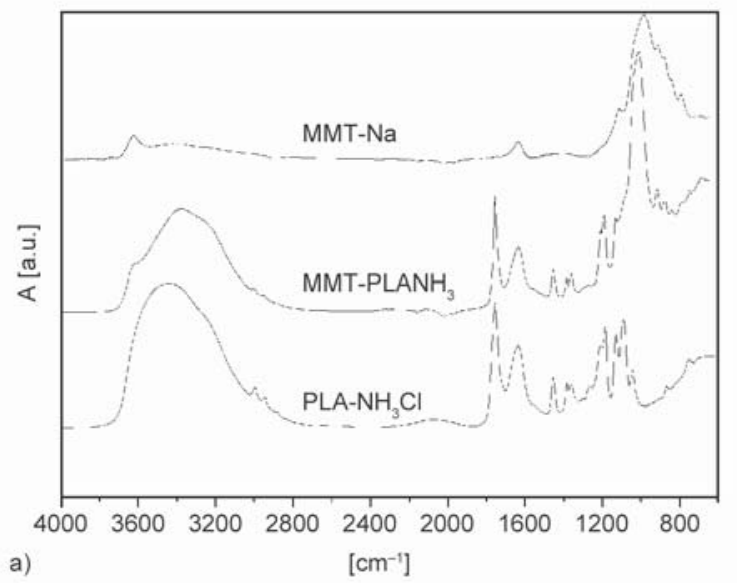

The OIt was determined by the onset of the exothermic oxidation reaction of PLA shown in the calorimetric curves. Three determinations were done for each sample and the OIt average number was reported. Number average molecular weight $\left(\bar{M}_{\mathrm{n}}\right)$ and weight average molecular weight $\left(\bar{M}_{\mathrm{w}}\right)$ as well as dispersity $(D)$ were determined using size exclusion chromatography (SEC), Agilent Technologies 1200 Series (Milan, Italy). The instrument was equipped with an Agilent degasser, an isocratic HPLC pump, an Agilent refractive index (RI) detector, and two PLgel $5 \mu \mathrm{m}$ MiniMIX-D columns conditioned at $35^{\circ} \mathrm{C}$. Chloroform $\left(\mathrm{CHCl}_{3}\right)$ was used as the mobile phase at a flow rate of $0.3 \mathrm{~mL} \cdot \mathrm{min}^{-1}$. The system was calibrated with polystyrene standards in a range from 500 to $3 \times 105 \mathrm{~g} \cdot \mathrm{mol}^{-1}$. Samples were dissolved in $\mathrm{CHCl}_{3}\left(2 \mathrm{mg} \cdot \mathrm{mL}^{-1}\right)$ and filtered through a $0.20 \mathrm{mi}-$ cron syringe filter before analysis. $M_{\mathrm{n}}$ and $M_{\mathrm{w}}$ were determined using Agilent ChemStation software.

\section{Results and discussion}

The successful organo-modification of both MMT and LDH was evidenced by ATR and XRD. In particular the ATR spectrum of hybrid product derived from MMT (MMT-PLANH 3 , Figure 2a) showed absorption bands ascribable to both surfactant and inorganic silicate. In particular a strong absorption at $1756 \mathrm{~cm}^{-1}$, due to the $\mathrm{C}=\mathrm{O}$ stretching of ester groups and peak at $1185 \mathrm{~cm}^{-1}$ attributable to asymmetric stretching of $\mathrm{C}-\mathrm{O}-\mathrm{C}$ were noticed together with a very strong signals at $987 \mathrm{~cm}^{-1}$ typical of the $\mathrm{Si}-\mathrm{O}$ stretching. The weak signals at 2997, 2946 and 1455 and $1380 \mathrm{~cm}^{-1}$ were ascribable to the stretching and bending of $-\mathrm{CH}_{3}$. The wide band centred at $3437 \mathrm{~cm}^{-1}$

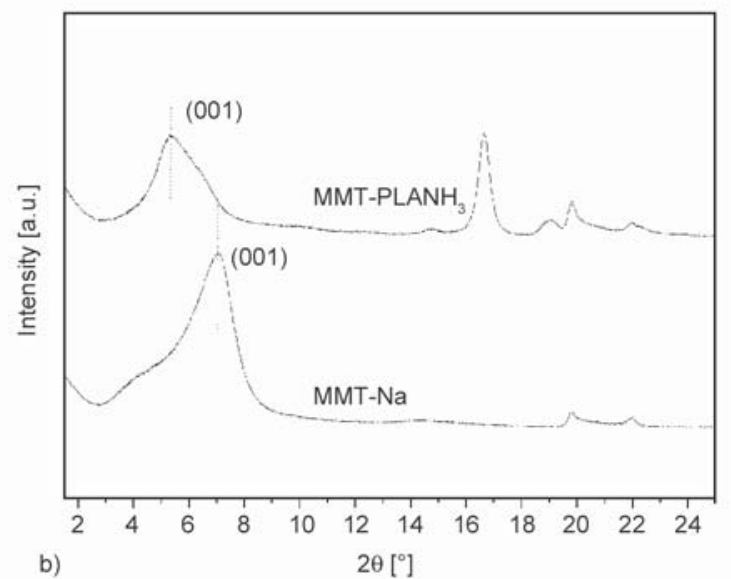

Figure 2. (a) ATR spectra of pristine montmorillonite (MMT-Na), the oligo PLA ( $\left.\mathrm{PLA}_{-} \mathrm{NH}_{3} \mathrm{Cl}\right)$ used as surfactant and the cationic exchange reaction product $\left(\mathrm{MMT}-\mathrm{PLANH}_{3}\right)$; (b) WAXD curves of pristine montmorillonite and MMT$\mathrm{PLANH}_{3}$ 
is due to the presence of water as well as the intense peak at $1638 \mathrm{~cm}^{-1}$ ascribable to the bending of $\mathrm{H}_{2} \mathrm{O}$ molecules between the layers. The shoulder at $3624 \mathrm{~cm}^{-1}$ is attributable to the stretching of $-\mathrm{OH}$ groups of the silicate, as clearly shown in the ATR spectrum of MMT-Na. This bands profile accounted for the presence of organo-modifier $\left(\mathrm{PLA}-\mathrm{NH}_{3}{ }^{+}\right)$in the MMT layers.

By comparing the WAXD patterns of MMT-Na and its modified hybrid derivative (Figure $2 b$ ) a relative displacement of basal peak (001) of the montmorillonite towards lower (20) angle was observed: the basal distance, calculated from Bragg's law passed from 1.25 to $1.65 \mathrm{~nm}$ confirming the intercalation of the organic oligomer between the platelets. The lowering and the enlargement of this diffraction peak suggested, moreover, a greater disorder degree in the stacking of the layers. At higher (20) angles, diffraction peaks ascribable to crystallized PLA chains were observed: the signals due to $(200 / 100)$ and (203) at 16.65 and $19.05^{\circ}$ were recognized and, on the basis of the attributions reported in the literature [18], referred the $\alpha$ form of PLA crystals.

To better investigate the effect of intercalation/immobilization within the MMT layers on the thermal features (especially onto the crystallization behaviour) of PLA oligomer, the PLA- $\mathrm{NH}_{3} \mathrm{Cl}$ and its corresponding MMT hybrid were analysed by DSC analysis (Figure 3). The PLA- $\mathrm{NH}_{3} \mathrm{Cl}$ sample showed thermal transitions ( $T_{\mathrm{g}}, T_{\mathrm{cc}}$ and $\left.T_{\mathrm{m}}\right)$ whose values and shape are in agreement with data reported in litera-

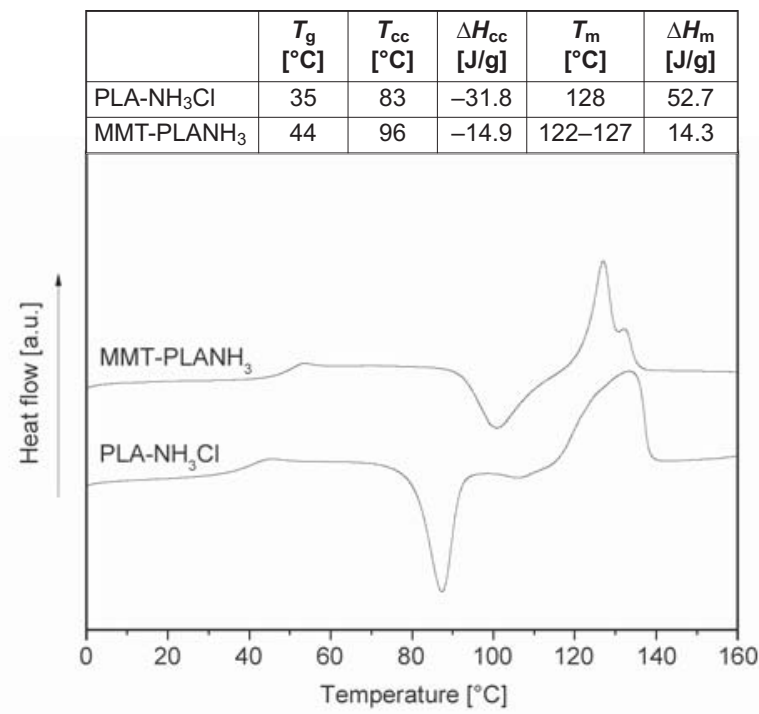

Figure 3. DSC curves (second heating) and thermal transitions data (inset Table) of PLA- $\mathrm{NH}_{3} \mathrm{Cl}$ before and after MMT-Na intercalation ture for PLA oligomers with similar molecular weight [19].

After intercalation in MMT-Na a remarkable increase of $T_{\mathrm{g}}$ value was noticed presumably due to oligochains confinement between the silicate platelets; the same effect is likewise responsible for the delay in the cold crystallization whose peak temperature resulted shifted more than 10 degrees towards higher temperature values. The strong interactions of PLA chains with surface layers, granted by cationic exchange reaction of ammonium end groups, presumably hindered the packing of chains into the crystal lattice providing even broader crystallization and melting peaks (see Figure 3); this latter showed a split peak ascribable to melting phenomenon of $\alpha$ homocrystals developed in PLLA during heating [20] and induced by the platelets interaction, [18] here observed even for PLA oligomers.

Likewise, the ATR spectrum of LDH-PLACOO (Figure 4a) showed absorptions due to the PLACOONa moiety thus confirming the hybrid nature of the collected LDH system. In particular, the peak at $1558 \mathrm{~cm}^{-1}$ is assigned to the stretching vibration of the carboxylate group $\left(\mathrm{C}=\mathrm{O}(\mathrm{O})^{-}\right)$, even if partially overlapped with broad signal at $1630 \mathrm{~cm}^{-1}$ due to the bending vibration of crystal water and to $\mathrm{C}=\mathrm{O} v$ mode of esters, visible as broad shoulder in the PLACOONa spectrum. The absorption peaks ranging between 2960 and $2850 \mathrm{~cm}^{-1}$ are reasonably due to the $-\mathrm{CH}_{2}$ and $-\mathrm{CH}_{3}$ stretching vibrations of the hydrocarbon groups. The band at $1385 \mathrm{~cm}^{-1}$ corresponding to the $v$ mode of $\mathrm{NO}_{3}{ }^{-}$is visible in both pristine $\mathrm{LDH}-$ $\mathrm{NO}_{3}$ and organo-LDH suggesting a co-intercalation mechanism, owing to incomplete exchange of nitrate with carboxylate anions.

The mean interlayer spacing of LDH-PLACOO obtained by WAXD pattern (Figure $4 \mathrm{~b}$ ) is $1.31 \mathrm{~nm}$ $\left(2 \theta=6.8^{\circ}\right)$ whereas the precursor $\mathrm{LDH}-\mathrm{NO}_{3}$ has a basal spacing of $0.89 \mathrm{~nm}$ corresponding to a sharp (003) reflection at $2 \theta=9.9^{\circ}$. The peaks at higher (20) angles, (006) and (009), reflected the formation of well-ordered PLA-COO intercalated LDH layers even if the presence of a slightly broad peak at about $11.6-12.0^{\circ}$ may suggest the presence of a carbonateintercalated crystalline phase that might be formed during the step of purification of the product or may be explained either by the distortion of the long organic chain or by a tilted chain with a higher angle related to the inorganic layer [21]. No signals due to the presence of crystallized PLA chains were here 

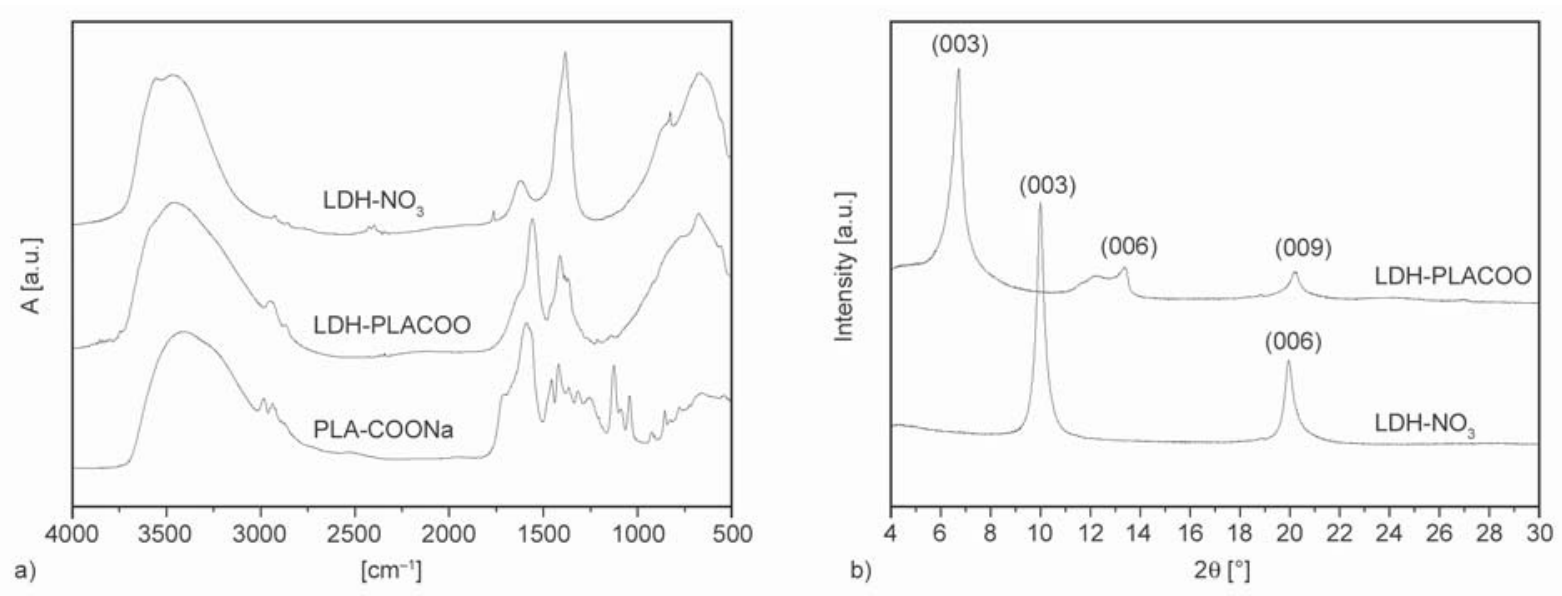

Figure 4. (a) ATR spectra of pristine hydrotalcite $\left(\mathrm{LDH}-\mathrm{NO}_{3}\right)$, the oligo PLA (PLA-COONa) used as surfactant and the anionic exchange reaction product (LDH-PLACOO); (b) WAXD curves of pristine hydrotalcite and LDH-PLACOO

noticed, presumably due to the very low $M_{\mathrm{w}}$ of this oligomer (PLA-COONa, see experimental part) which did not show any melting behaviour when analysed with DSC. Eventual $T_{\mathrm{g}}$ transition was overlapped by a broad signal ascribable to presence of water molecules.

The TGA/DTG curves (collected under air flow) of both hybrids and their corresponding starting materials (pristine inorganic substrate and surfactant) are reported in Figure 5. The degradation of MMT$\mathrm{PLANH}_{3}$ (Figure 5a) showed mainly a one-step path in the range of temperatures between 230 and $400^{\circ} \mathrm{C}$, totally ascribable to the presence of surfactant (as shown by the blue curve). By comparing the temperatures related to the maximum degradation rate (from DTG curves) we observed a remarkable increase of the thermal stability of intercalated oligo-esters with respect to the free-ones, suggesting that the anchoring between the layers protects the surfactant by delaying their degradation. By considering the residual percentages at $600{ }^{\circ} \mathrm{C}$ of MMT-Na and MMT-
$\mathrm{PLANH}_{3}$, and their respective water losses below $100^{\circ} \mathrm{C}$, an organic content of $29 \%$ for the hybrid was evaluated.

More complex is the degradation path of LDH-PLA$\mathrm{COO}$ owing to either pristine materials profiles $\mathrm{LDH}-$ $\mathrm{NO}_{3}$ and PLA-COONa. The thermogravimetric trace of $\mathrm{LDH}_{-\mathrm{NO}_{3}}$ (Figure 5b) evidences a two steps decomposition process, where the first weight loss step, up to $250^{\circ} \mathrm{C}$, is attributed to the loss of adsorbed and intercalated water molecules, whereas the second weight loss step, between 250 and $550^{\circ} \mathrm{C}$ corresponds to the loss of the interlayer nitrate ions and to the dehydroxylation of the metal hydroxide layers [16].

The thermal decomposition of PLA-COONa is characterized by different steps accounting to volatile and adsorbed water losses up to $200^{\circ} \mathrm{C}$ and main steps between 307 and $590^{\circ} \mathrm{C}$. This degradation path differing from that of PLA [13] can be rationalized by considering the nature/ structure of end groups (sodium carboxylate functionalities able to probably generate salts during the decomposition of the oligomer

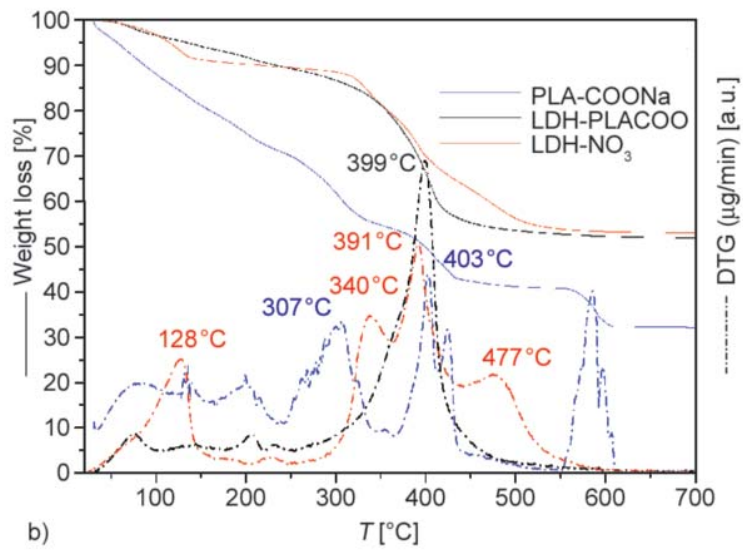

Figure 5. TGA/DTG curves of (a) MMT-PLANH 3 and its reagents, (b) LDH-PLACOO and its reagents 
backbone) and the low molecular weight that it has been reported as responsible of the decrease in thermal stability of PLA [13]. The thermal decomposition of the LDH-PLACOO mainly takes place in one-step between 300 and $550^{\circ} \mathrm{C}$ even if a weight loss at lower temperatures was clearly evident. In particular, up to $180^{\circ} \mathrm{C}$, the loss of the surface and crystal water molecules located in the interlayer region can be supposed, while different degradation reactions up to the formation of metal oxides can be considered as the most important step. This stage involves the decomposition of the intercalated PLACOONa molecules, the loss of some interlayer carbonate ions interfering with partial dihydroxylation of the layered LDH (up to $550^{\circ} \mathrm{C}$ ), and then the complete dehydroxylation process of the layered LDH.
The amount of oligo-ester surfactant molecules anchored to the LDH was calculated considering the weight loss associated with the organic material decomposition by taking into account the dehydroxylation process whose weight loss was previously estimated [16]. Accordingly, the quantity of intercalated PLA-COONa anions was about $25 \mathrm{wt} \%$.

The hybrids were dispersed, by using a solution procedure, into PLA matrix. Two different inorganic contents ( 1 and $2 \mathrm{wt} \%$ calculated by taking into account the hybrids organic compounds quantity) were provided. Morphological features investigated by XRD and TEM showed a quite good dispersion of the hybrids, even if in both composite series the presence of large aggregates and tactoids was evidenced despite the apparent macroscopic homogeneity (photos

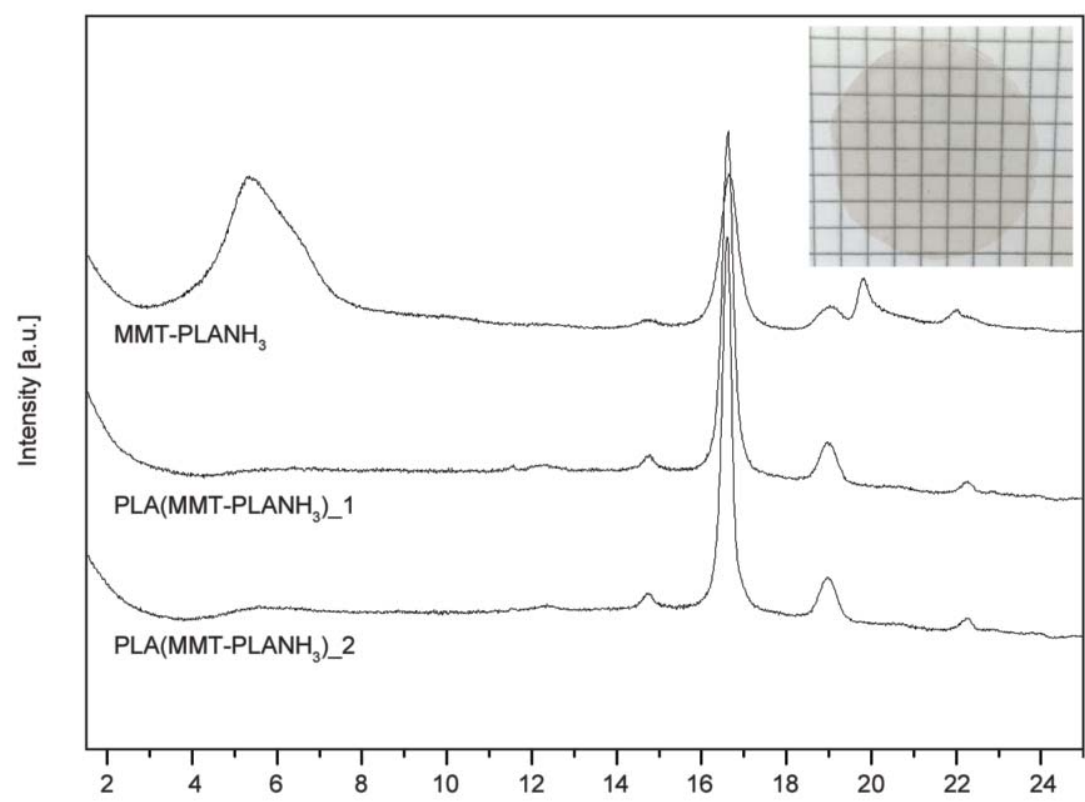

a)

$2 \theta\left[^{\circ}\right]$
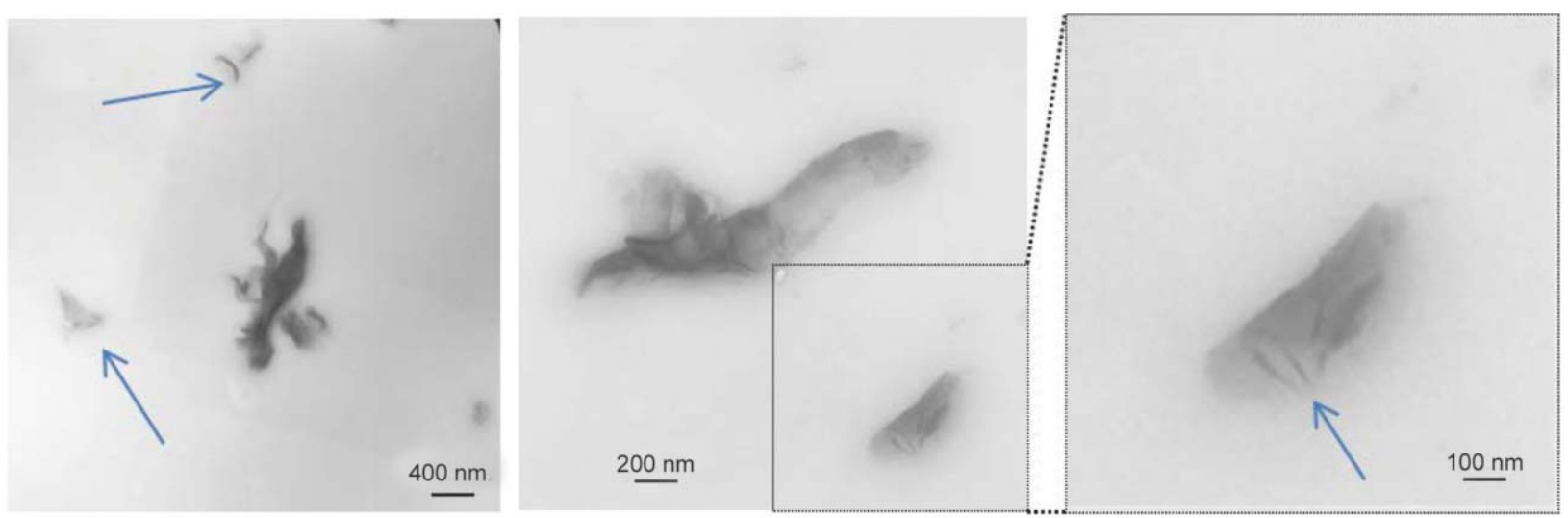

b)

Figure 6. (a) XRD curves of pristine modified MMT-PLANH 3 and composites PLA-based containing 1 and 2 wt $\%$ of inorganic content (MMT) calculated on the basis of hybrid composition; inset photo of composite film containing $2 \mathrm{wt} \%$ of MMT; (b) TEM analysis at different magnifications of the sample containing $1 \mathrm{wt} \%$ of MMT 
of films as inset in the figures 6 and 7), in agreement with previous literature [14, 22].

Specifically the PLA composites obtained by dispersing the MMT-PLANH 3 were easily treated by compression molding resulting in transparent and homogeneous weakly browned films (inset in the Figure 6a). The XRD analysis showed a really small shoulder in the $2 \theta$ angle range characteristic of the broader diffraction peak of pristine modified clay, suggesting a substantial intercalated structure. TEM analysis (Figure 6b) evidenced the presence of single lamellae (indicated by arrows) together with large aggregates whose intercalation by polymer chains was evidenced at higher magnification.

The composites containing the LDH hybrid provided homogeneous and actually uncoloured, transparent films with really good uniformity (inset Figure 7a).
The XRD curves showed the presence of a small diffraction peak at about $5.9^{\circ}$ in agreement with a basal spacing of $1.5 \mathrm{~nm}$, stating the presence of an intercalated polymer fraction for both composite compositions. TEM analysis evidenced, instead, a large number of well-dispersed single lamellae (see arrows) coexisting with larger aggregates, whose dimension are in agreement with kind of pristine inorganic substrate (smaller than MMT pristine clay).

Therefore both composites series (from MMT and LDH hybrids dispersion) showed mainly intercalated morphology with a level of dispersion ranging from micro aggregates to small tactoids with dimensions less than hundred nanometers, till to a consistent number of very small piled layers and single lamellas.

The glass transition temperatures and crystallization temperature as well as the melting behaviour were
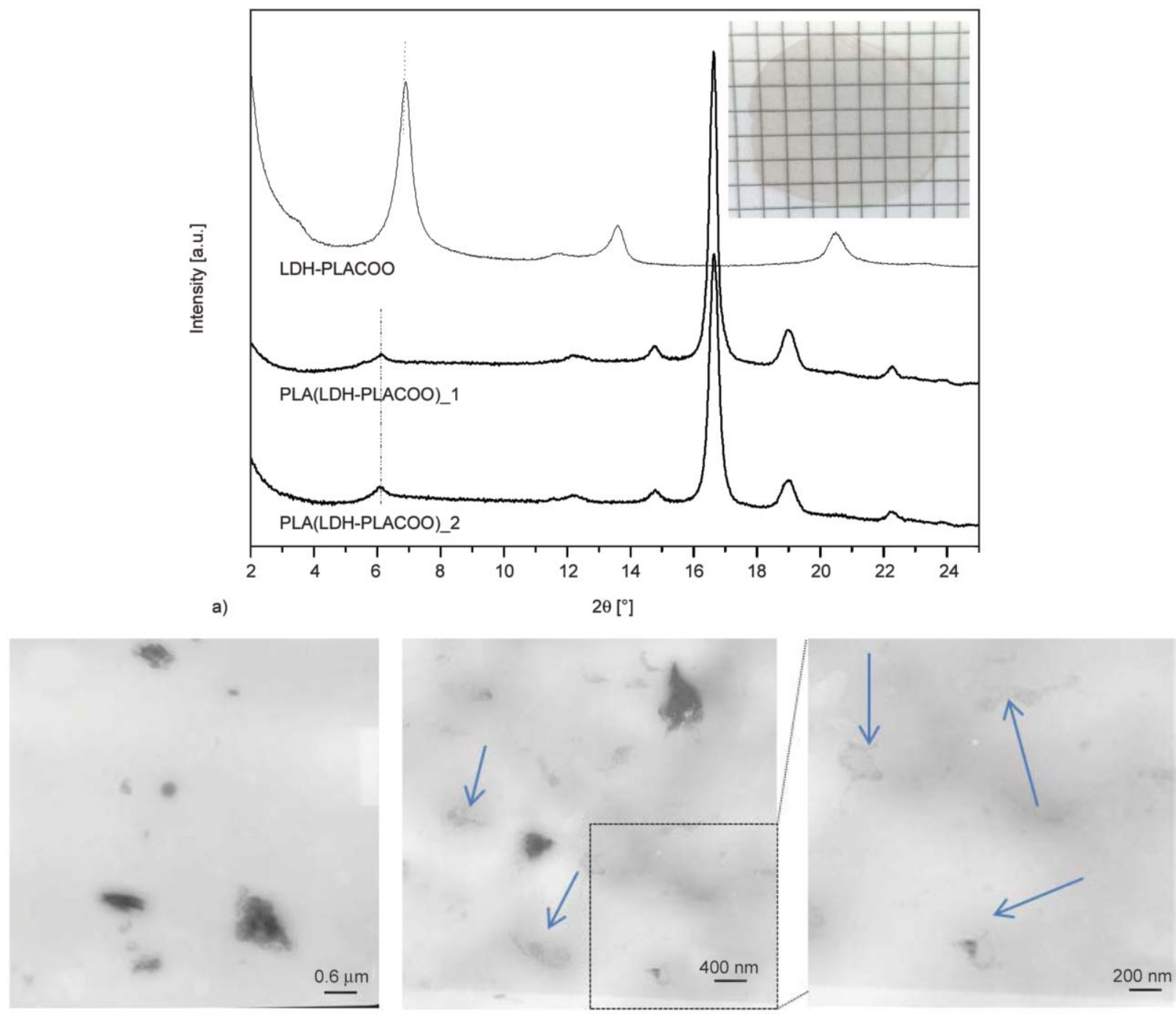

b)

Figure 7. (a) XRD curves of pristine modified LDH-PLACOO and composites PLA-based containing 1 and 2 wt $\%$ of inorganic content $(\mathrm{LDH})$ calculated on the basis of hybrid composition; inset photo of composite film containing $2 \mathrm{wt} \%$ of LDH; (b) TEM analysis at different magnifications of the sample containing $1 \mathrm{wt} \%$ of LDH 
Table 1. Thermal transition of PLA composites, $T_{\mathrm{g}}, T_{\mathrm{cc}}$ and $T_{\mathrm{m}}$ values; their related enthalpy values and crystallinty

\begin{tabular}{|c|c|c|c|c|c|c|c|c|c|c|}
\hline \multirow[b]{2}{*}{ Sample } & \multicolumn{6}{|c|}{ Before annealing } & \multicolumn{4}{|c|}{ After annealing ${ }^{*}$} \\
\hline & $\begin{array}{c}T_{\mathbf{g}} \\
{\left[{ }^{\circ} \mathbf{C}\right]}\end{array}$ & $\begin{array}{c}T_{\mathrm{cc}} \\
{\left[{ }^{\circ} \mathbf{C}\right]}\end{array}$ & $\begin{array}{l}\Delta \boldsymbol{H}_{\mathbf{c c}} \\
{[\mathbf{J} / \mathbf{g}]}\end{array}$ & $\begin{array}{c}\boldsymbol{T}_{\mathbf{m}} \\
{\left[{ }^{\circ} \mathbf{C}\right]}\end{array}$ & $\begin{array}{l}\Delta \boldsymbol{H}_{\mathrm{m}} \\
{[\mathbf{J} / \mathbf{g}]}\end{array}$ & $\begin{array}{c}\chi \\
{[\%]}\end{array}$ & $\begin{array}{c}T_{\mathbf{g}} \\
{\left[{ }^{\circ} \mathbf{C}\right]}\end{array}$ & $\begin{array}{c}T_{\mathrm{m}} \\
{\left[{ }^{\circ} \mathbf{C}\right]}\end{array}$ & $\begin{array}{l}\Delta \boldsymbol{H}_{\mathbf{m}} \\
{[\mathbf{J} / \mathbf{g}]}\end{array}$ & $\begin{array}{c}\chi \\
{[\%]}\end{array}$ \\
\hline PLA_son & 59.2 & 109.8 & -23.9 & $147.8-154.6$ & 25.0 & 1.1 & 59.0 & $148.8-155.3$ & 35.0 & 37.6 \\
\hline PLA(MMT-PLANH $\left.{ }_{3}\right) \_1$ & 59.0 & 113.3 & -25.7 & $149.1^{* *}$ & 27.6 & 2.0 & 60.5 & $147.5-153.6$ & 38.9 & 41.4 \\
\hline PLA(MMT-PLANH $\left.{ }_{3}\right) \_2$ & 58.7 & 113.6 & -33.0 & $148.6^{* *}$ & 35.9 & 3.0 & 59.3 & $147.4-153.7$ & 44.8 & 47.2 \\
\hline PLA(LDH-PLACOO)_1 & 59.4 & 113.0 & -19.8 & $148.7^{* *}$ & 22.8 & 3.1 & 60.6 & $146.9-152.9$ & 31.6 & 33.6 \\
\hline PLA(LDH-PLACOO) 2 & 59.5 & 114.7 & -22.4 & $149.0^{* *}$ & 24.0 & 1.7 & 60.6 & $147.4-153.5$ & 30.8 & 32.4 \\
\hline
\end{tabular}

${ }^{*}$ Samples treated in the oven at $110^{\circ} \mathrm{C}$ for $8 \mathrm{hrs}$.

** doubled, really broad peak

evaluated by DSC before and after annealing (Table 1).

It is well known that dispersion of nanofillers in polymer matrix may influence on the $T_{\mathrm{g}}$ values, crystallization kinetics, morphology and degree of crystallinity, being the effect more significant when the interactions between polymer chains and filler surface are particularly extensive. All the composites showed no significant variation of $T_{\mathrm{g}}$ values; the immobilization of macromolecular chains on the layers surface is probably balanced by plasticizing owing to oligoPLA used as surfactant, [19] at least for the MMT-based composites. Before annealing, all the composites were substantially amorphous suggesting no significant effect on the overall crystallinity. Interestingly the $T_{\mathrm{cc}}$ values are slightly enhanced with respect to that of PLA matrix, contrary to data generally obtained (showing a decrease of $T_{\mathrm{cc}}$ ) and invoking nucleation effects [23] mainly due to intercalated morphologies. Stronger interactions and consequently exfoliated morphologies accounted for a different behaviour, as here observed, and resulting in a delayed crystallization [24, 25]. After annealing the $T_{\mathrm{g}}$ values increased as result of increased amorphous rigid fraction owing to raised crystallinity. The enthalpy value associated to melting transition was lower for the composites obtained by using LDHPLACOO hybrid in comparison with the PLA matrix. This can be attributed, as first hypothesis, to a higher disorder degree induced by lamellae dispersion hindering the packing of crystals and preventing complete crystallization, especially for highly intercalated/exfoliated morphologies; however an effect of the molecular weight evolution (decreased for the same composites, see Table 2) should be taken into account. Accordingly, the increased crystallinity of sample PLA(MMT-PLANH 3 )_1 and PLA(MMT$\left.\mathrm{PLANH}_{3}\right)_{2} 2$ could be due to the exfoliated morphologies better allowing the growing of crystal domains. However, at the chosen annealing temperature, the crystalline domains exist in both forms $\alpha$ and $\alpha^{\prime}$ with prevalence of the form $\alpha^{\prime}$, the metastable crystalline phase having different associated enthalpy value with respect to more ordered $\alpha$ form [26]; by taking into account that the transition of the $\alpha^{\prime}$ to the $\alpha$-form depends only on the temperature and annealing time, the differences observed for the composites, all treated in the same experimental conditions, could be attributed to the presence of the hybrid and its dispersion degree in the polymer matrix [18].

By highlighting the XRD curves of the composites in region of PLA diffraction peaks (focusing on

Table 2. Molecular weight analysis and thermal stability of PLA-based composites

\begin{tabular}{|c|c|c|c|c|c|c|}
\hline Sample & $\begin{array}{c}\overline{M_{\mathrm{n}}} \\
{[\mathrm{kDa}]}\end{array}$ & $\begin{array}{c}\bar{M}_{\mathrm{w}} \\
{[\mathrm{kDa}]}\end{array}$ & $\begin{array}{c}T_{\text {onset }} \\
{\left[{ }^{\circ} \mathbf{C}\right]}\end{array}$ & $\begin{array}{l}T_{\text {inf }}{ }^{1} \\
{\left[{ }^{\circ} \mathrm{C}\right]}\end{array}$ & $\begin{array}{l}\text { Char }^{2} \\
\text { [wt\%] }\end{array}$ & $\begin{array}{c}\text { OIt } \\
{[\mathrm{min}]}\end{array}$ \\
\hline PLA & 130 & 220 & 341.0 & 362.3 & 0 & - \\
\hline PLA_son & 124 & 208 & 337.0 & 362.7 & 0 & $0.5 \pm 0.1$ \\
\hline PLA(MMT-PLANH $\left.{ }_{3}\right) 1$ & 127 & 206 & 335.0 & 362.6 & 0.9 & $0.8 \pm 0.1$ \\
\hline PLA(MMT-PLANH $\left.{ }_{3}\right)_{2} 2$ & 131 & 203 & 337.9 & 362.3 & 2.1 & $7.2 \pm 0.6$ \\
\hline PLA_MMT & 136 & 236 & 336.8 & 364.7 & 1.8 & - \\
\hline PLA(LDH-PLACOO)_1 & 106 & 184 & 311.3 & 335.8 & 1.3 & $0.5 \pm 0.0$ \\
\hline PLA(LDH-PLACOO)_2 & 99 & 187 & 296.0 & 322.3 & 2.6 & $\mathrm{nd}^{3}$ \\
\hline PLA_PLA-COONa & 101 & 181 & 328.6 & 362.6 & 0 & $0.5 \pm 0.0$ \\
\hline PLA LDH & 131 & 234 & 315.0 & 335.7 & 2.3 & - \\
\hline
\end{tabular}

${ }^{1}$ Calculated from DTG curves; ${ }^{2}$ determined at $650{ }^{\circ} \mathrm{C} ;{ }^{3}$ Immediate oxidation after the gas switching was observed 

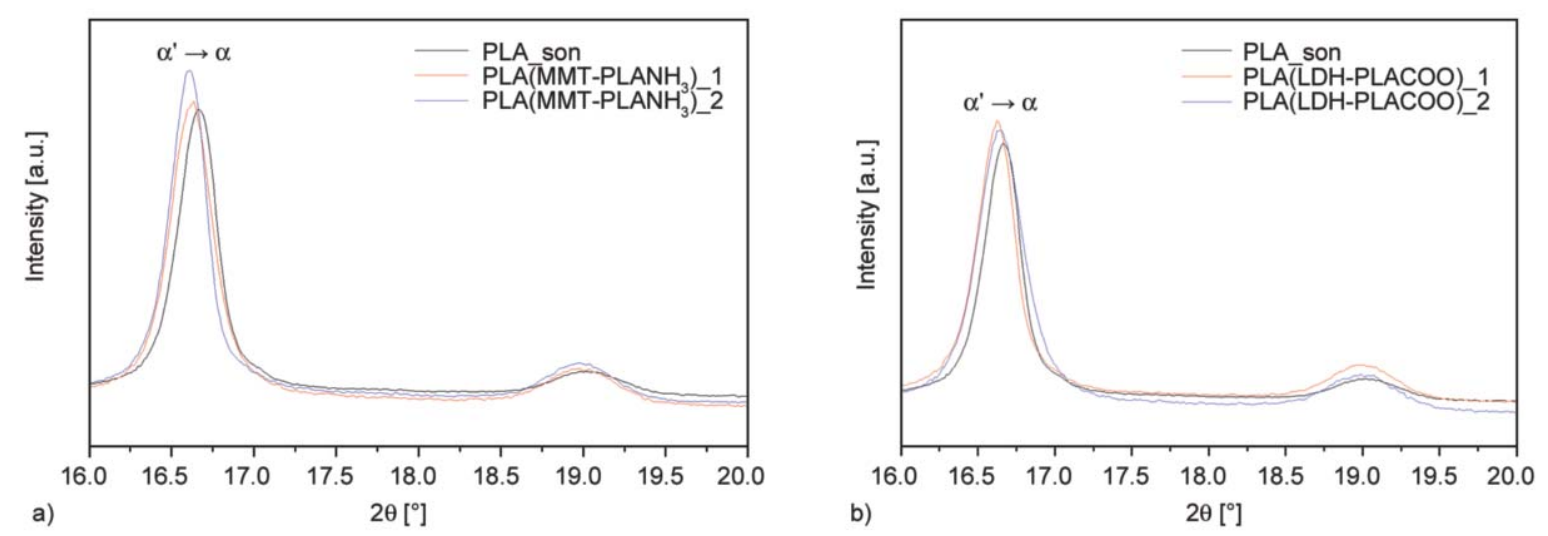

Figure 8. XRD curves in the $2 \theta$ range from 16.0 to $20.5^{\circ}$ of PLA_son and its composites

$(110) /(200)$ and $(203) /(113))$ it appeared evident that both the clays favoured the formation of $\alpha^{\prime}$ with respect to PLA matrix, as proved by the peaks shifting to lower angle (Figure 8) [20], whose amount, being difficult to be quantified, can certainly affect the final crystallinity data.

The analysis of structural and thermal stability of the polymer matrix owing hybrids dispersion evidenced different features depending on the nature of inorganic substrates (MMT-PLANH 3 and LDH-PLACOO) (Table 2).

By analysing the molecular weight (MW) evolution of starting PLA following the dispersion of the hybrids, a substantial invariance for the composites containing MMT was observed with respect to blank experiment (PLA_son). Instead, the dispersion of LDH-PLACOO provided composites with a sharp decrease of both $\overline{M_{\mathrm{n}}}$ and $\bar{M}_{\mathrm{w}}$ of PLA, suggesting the occurrence of some PLA chain breaking.

To better investigate this behaviour two additional blank experiments were carried out, with the aim of simulating the effects of interactions between the polymer chains and either the inorganic LDH surface and the oligoester surfactant onto PLA MW evolution. The use of not-modified LDH (providing the sample PLA_LDH) seemed do no provoke degradation effect of the matrix, at least performing both the filler dispersion and the analysis at room temperature, without heating. Instead, the dispersion of PLACOONa oligomer in the polymer matrix provoked PLA breaking reactions due to hydrolysis [27], triggered by the same PLA-COONa, that even if dried in the oven, it contained residual water traces not easily be removed (see TGA evidences). On the other hand it is known that the presence of terminal carboxyl groups can autocatalyse the reaction of ester hydrolysis [28].The thermo-oxidative stability of all composites was investigated by TGA under air and OIt measurements. A one-step process was observed for all formulations, whose char residues were in agreement with composites composition (Table 2). The thermal feature of the composites containing the LDH-PLACOO hybrid was poor. A noticeable decrease of both $T_{\text {onset }}$ and $T_{\text {inf }}$ was observed. This behaviour, already discussed in literature [22] and reported as more extensive for carboxylate LDH in comparison with unmodified one [10], is consistent with the reduced $\overline{M_{\mathrm{n}}}$ values [13] for all the PLA samples containing the surfactant (free or exchanged in the LDH layers) and several reports invoking the random degradation caused by $\mathrm{Mg}(\mathrm{OH})_{2}$ on the layer surfaces [29] and the PLA degradation temperature decrease induced by $\mathrm{MgO}$ formed from hydroxide [30]. A further deeper insight in the result was here approached by comparing the thermal degradation paths of PLA_PLA-COONa and PLA_LDH with those of composites by taking into account the single possible interactions between the components of the system as established by the intercalation process (Table 2 and Figure 9). Precisely, the intercalation process of PLA between the organo-modified LDH (LDH-PLACOO) provides specific interactions between PLA chains and surfactant (PLA-COONa) as well as between PLA chains and inorganic surface (LDH) (inset in Figure 9) whose role in the degradation path of the nanocomposites can be evidenced by analysing the TG curves of respectively PLA_PLACOONa and PLA_LDH samples (Figure 9).

The compound's thermal behaviour during the heating showed that the addition of end-carboxylate oligo-ester (sample PLA_PLA-COONa) and unmodified LDH (sample PLA_LDH) negatively affected the thermal stability of the PLA (Figure 9 and Table 2). In both cases a substantial decrease of characteristic 


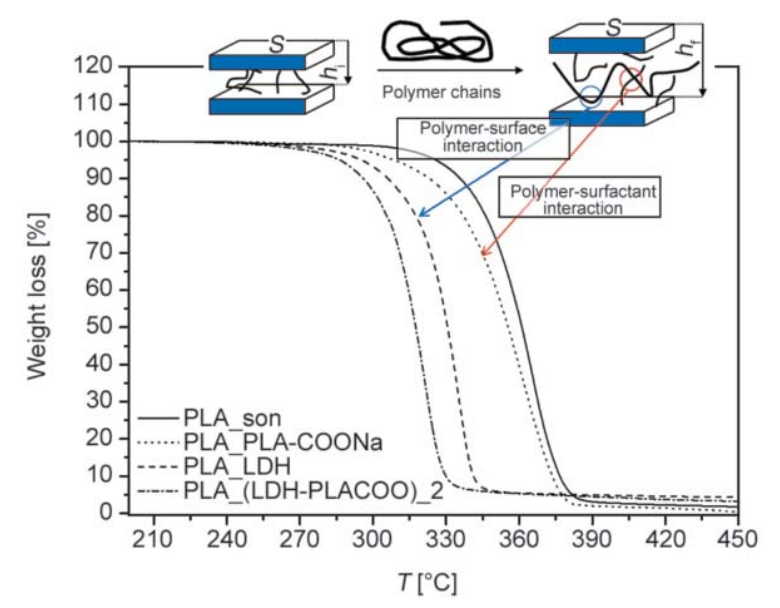

Figure 9. Degradation curves (from TGA) of samples PLAbased containing the surfactant (sample PLA_PLACOONa) and the unmodified LDH (sample PLA$\mathrm{LDH}$ ) in comparison with those of PLA and the composite PLA_(LDH-PLACOO)_2. Inset schematic representation of intercalation process

degradation temperatures with respect to starting PLA (or blank sample PLA_son) was observed. Consequently the thermal behaviour of the composites (PLA_LDH-PLACOO_1 and PLA_LDH-PLACOO_2) can be considered as the result of the specific interactions of PLA chains with both the LDHhybrid components due to the intercalation process (see scheme as inset in Figure 9): the polymer chains are interacting with surfactant and with filler surface. Indeed, the presence of a surfactant capable of driving specific interactions with the PLA from one side is able to grant and promote a good dispersion degree of LDH platelets (as showed by morphological analysis), owing to facilitated polymer chains intercalation; from the other side by increasing the extent of PLA chain intercalation, the interactions with the inorganic platelets provoked the degradation effect typically induced by the surface functionalities of inorganic substrates that was observed. Accordingly, the OIt measurements did not show any benefit stemming from LDH (PLA_LDH) and its dispersion (PLA_(LDH-PLACOO)_1 and PLA_(LDH-PLACOO)_2) (see Table 2).

Instead, the addition of MMT-PLANH ${ }_{3}$, even if seemingly does not improve the thermal performance of the PLA matrix, as already reported in literature for PLA-based composites with MMT clays having similar morphologies [18, 22, 31], preserved the thermal stability of the PLA and showed a significant effect onto the OIT results. In particular, with reference to nanocomposites obtained by commercial organophilic MMT, Wu et al. [32] reported even a decrease in the stability and Nieddu et al. [33] fluctuating results depending on the content of inorganic clay and presumably on the morphology. It has been reported that the poor enhancement in thermo-oxidative stability given by some organo-MMT to PLA-composites could be linked to the fact that clay may act as heat barrier only at the beginning of the thermal decomposition and for low temperatures. At higher temperatures the silicate layers could accumulate heat and then promote the degradation process [31]. In this case by using MMT modified by oligoPLA, it appears evident that, in the range of employed composition, the thermal stability of the matrix remained unchanged since the initial stages of the degradation pathway. Furthermore, the OIt measurements allow investigating the behaviour at relatively low temperature $\left(230^{\circ} \mathrm{C}\right)$ during the time and then, in this condition, the capability of dispersed MMT layers to protect the PLA from heat and oxygen is proved (Table 2). Such evidence is due to gas barrier activity exerted not only by dispersed clay layers [34] but even by confined polymer chains as previously stated for different polymer matrix [35] and here demonstrated even for PLA. By increasing the content of MMT-PLANH ${ }_{3}$ the oxidation time (OIt, Table 2) was remarkably increased, confirming such behaviour and definitely assessing that the use of MMThybrids with surfactant able to specifically interact with PLA polymer is able to provide nanocomposites with good dispersion and improved oxidation stability.

\section{Conclusions}

Surfactants tailored to enhance the interfacial interactions between PLA chains and inorganic nanostructured substrates were prepared and preliminary tested to provide PLA-based nanocomposites. In particular, oligo-esters bearing end groups suitable to be ionically exchanged with cationic and anionic clays were synthetized and accordingly two hybrids based on MMT and LDH were obtained. The XRD and FTIR characterizations confirmed the successful intercalation of similar amount of oligo-PLA that resulted anchored to nanolayers surface. Both the hybrids were dispersed in PLA matrix providing nanocomposites with intercalated/exfoliated morphologies, but different structural and thermal stability. In particular while the composites with MMT proved to be stable under thermo-oxidative conditions, suggesting that the surfactant-modulated interfacial interactions can 
optimize their ultimate properties, the samples obtained by dispersing the LDH hybrid suffered from MW decreasing, negatively affecting their final thermostability. Deeper insights about the effect of interactions at interface promoted by oligoester used as surfactant led to the conclusion that a certain extent of PLA hydrolysis triggered by both surfactant and inorganic surface (LDH) cannot be completely avoided. Also, this effect seemed more extensive by improving the interactions between all the components.

\section{Acknowledgements}

Prof. Dr. Piet J. Dijkstra, Developmental BioEngineering, MIRA Institute for Biomedical Technology and Technical Medicine, University of Twente, NL) is acknowledged for his suggestions about the synthesis of PLA-NH3Cl sample. MIUR (PRIN 2008) contract grant number 200898KCKY and FP7 Large Cooperation Grant Agreement (DIBBIOPACK) number 280676 were acknowledged for funding.

\section{References}

[1] Kuila T., Tripathy T., Hee Lee J.: Polyolefin-based polymer nanocomposites. in 'Advances in polymer nanocomposites' (ed.: Gao F.) Woodhead, Cambridge, 181215 (2012).

https://doi.org/10.1533/9780857096241.2.181

[2] Choi H., Ray S.: A review on melt-state viscoelastic properties of polymer nanocomposites. Journal of Nanoscience and Nanotechnology, 11, 8421-8449 (2011). https://doi.org/10.1166/jnn.2011.4880

[3] Coiai S., Prevosto D., Bertoldo M., Conzatti L., Causin V., Pinzino C., Passaglia E.: Chemistry of interfacial interactions in a LDPE-based nanocomposite and their effect on the nanoscale hybrid assembling. Macromolecules, 46, 1563-1572 (2013).

https://doi.org/10.1021/ma301689h

[4] Drumright R. E., Gruber P. R., Henton D. E.: Polylactc acid technology. Advanced Materials, 12, 1841-1846 (2000).

https://doi.org/10.1002/1521-4095(200012)12:23<1841::AIDADMA1841>3.0.CO;2-E

[5] Ray S. S.: Polylactide-based bionanocomposites: A promising class of hybrid materials. Accounts of Chemical Research, 45, 1710-1720 (2012).

https://doi.org/10.1021/ar3000376

[6] Reddy M. M., Vivekanandhan S., Misra M., Bhatia S. K., Mohanty A. K.: Biobased plastics and bionanocomposites: Current status and future opportunities. Progress in Polymer Science, 38, 1653-1689 (2013).

https://doi.org/10.1016/j.progpolymsci.2013.05.006
[7] Rhim J-W., Park H-M., Ha C-S.: Bio-nanocomposites for food packaging applications. Progress in Polymer Science, 38, 1629-1652 (2013).

https://doi.org/10.1016/j.progpolymsci.2013.05.008

[8] Pluta M., Paul M-A., Alexandre M., Dubois P.: Plasticized polylactide/clay nanocomposites. I. The role of filler content and its surface organo-modification on the physico-chemical properties. Journal of Polymer Science Part B: Polymer Physics, 44, 299-311 (2006).

https://doi.org/10.1002/polb.20694

[9] Cumkur E. A., Baouz T., Yilmazer U.: Poly(lactic acid)layered silicate nanocomposites: The effects of modifier and compatibilizer on the morphology and mechanical properties. Journal of Applied Polymer Science, 132, 42553/1-42553/12 (2015). https://doi.org/10.1002/app.42553

[10] Scaffaro R., Botta L., Passaglia E., Oberhauser W., Frediani M., Di Landro L.: Comparison of different processing methods to prepare poly(lactid acid)-hydrotalcite composites. Polymer Engineering and Science, 54, 1804-1810 (2014).

https://doi.org/10.1002/pen.23724

[11] Coiai S., Passaglia E., Pucci A., Ruggeri G.: Nanocomposites based on thermoplastic polymers and functional nanofiller for sensor applications. Materials, 8, 33773427 (2015).

https://doi.org/10.3390/ma8063377

[12] Pérez Amaro L., Cicogna F., Passaglia E., Morici E., Oberhauser W., Al-Malaika S., Dintcheva N. T., Coiai S.: Thermo-oxidative stabilization of poly(lactic acid) with antioxidant intercalated layered double hydroxides. Polymer Degradation and Stability, 133, 92-100 (2016). https://doi.org/10.1016/j.polymdegradstab.2016.08.005

[13] Carrasco F., Gámez-Pérez J., Santana O. O., Maspoch M. L.: Processing of poly(lactic acid)/organomontmorillonite nanocomposites: Microstructure, thermal stability and kinetics of the thermal decomposition. Chemical Engineering Journal, 178, 451-460 (2011). https://doi.org/10.1016/j.cej.2011.10.036

[14] Neppali R., Causin V., Marega C., Modesti M., Adhikari R., Schilyssek S., Ray S. S., Marigo A.: The effect of different clays on the structure, morphology and degradation behavior of poly(lactic acid). Applied Clay Science, 87, 278-284 (2014). https://doi.org/10.1016/j.clay.2013.11.029

[15] ten Breteler M. R., Feijen J., Dijkstra P. J., Signori F.: Synthesis and thermal properties of hetero-bifunctional PLA oligomers and their stereocomplexes. Reactive and Functional Polymers, 73, 30-38 (2013). https://doi.org/10.1016/j.reactfunctpolym.2012.10.003

[16] Muksing N., Magaraphan R., Coiai S., Passaglia E.: Effect of surfactant alkyl chain length on the dispersion, and thermal and dynamic mechanical properties of LDPE/organo-LDH composites. Express Polymer Letters, 5, 428-448 (2011). https://doi.org/10.3144/expresspolymlett.2011.42 
[17] Fischer E. W., Sterzel H. J., Wegner G.: Investigation of the structure of solution grown crystals of lactide copolymers by means of chemical reactions. KolloidZeitschrift und Zeitschrift für Polymere, 251, 980-990 (1973). https://doi.org/10.1007/BF01498927

[18] Saiter A., Delpouve N., Dargent E., Oberhauser W., Conzatti L., Cicogna F., Passaglia E.: Probing the chain segment mobility at the interface of semi-crystalline polylactide/clay nanocomposites. European Polymer Journal, 78, 274-289 (2016).

https://doi.org/10.1016/j.eurpolymj.2016.03.040

[19] Burgos N., Tolaguera D., Fiori S., Jiménez A: Synthesis and characterization of lactic acid oligomers: Evaluation of performance as poly(lactic acid) plasticizers. Journal of Polymers and the Environment, 22, 227-235 (2014). https://doi.org/10.1007/s10924-013-0628-5

[20] Yasuniwa M., Sakamo K., Ono Y., Kawahara W.: Melting behavior of poly(L-lactic acid): X-ray and DSC analyses of the melting process. Polymer, 49, 1943 1951 (2008). https://doi.org/10.1016/j.polymer.2008.02.034

[21] Carbajal Arizaga G. G., Mangrich A. S., Ferreira da Costa Gardolinski J. E., Wypych F.: Chemical modification of zinc hydroxide nitrate and $\mathrm{Zn}-\mathrm{Al}$-layered double hydroxide with dicarboxylic acids. Journal of Colloid and Interface Science, 320, 168-176 (2008). https://doi.org/10.1016/j.jcis.2007.12.038

[22] Katiyar V., Gerds N., Koch C. B., Risbo J., Hansen H. C. B., Plackett D.: Melt processing of poly(L-lactic acid) in the presence of organomodified anionic or cationic clays. Journal of Applied Polymer Science, 122, 112-125 (2011).

https://doi.org/10.1002/app.33984

[23] Picard E., Espuche E., Fulchiron R.: Effect of an organomodified montmorillonite on PLA crystallization and gas barrier properties. Applied Clay Science, 53, 58-65 (2011). https://doi.org/10.1016/j.clay.2011.04.023

[24] Dìaz A., Franco L., Casas M. T., del Valle L. J., Aymamì J., Olmo C., Puiggali J.: Preparation of micro-molded exfoliated clay nanocomposites by means of ultrasonic technology. Journal of Polymer Research, 21, 584-596 (2014). https://doi.org/10.1007/s10965-014-0584-3

[25] Krikorian V., Pochan D. J.: Unusual crystallization behavior of organoclay reinforced poly(L-lactic acid) nanocomposites. Macromolecules, 37, 6480-6491 (2004). https://doi.org/10.1021/ma049283w
[26] Righetti M. C., Gazzano M., Di Lorenzo M. L., Androsch R.: Enthalpy of melting of $\alpha^{\prime}$ - and $\alpha$-crystals of poly(L-lactic acid). European Polymer Journal, 70, 215-220 (2015). https://doi.org/10.1016/j.eurpolymj.2015.07.024

[27] Al-Itry R., Lamnawar K., Maazouz A.: Improvement of thermal stability, rheological and mechanical properties of PLA, PBAT and their blends by reactive extrusion with functionalized epoxy. Polymer Degradation and Stability, 97 1898-1914 (2012). https://doi.org/10.1016/j.polymdegradstab.2012.06.028

[28] Vert M.: Lactic acid-based degradable polymers. in 'Handbook of biodegradable polymers' (ed.: Bastioli C.) Rapra, Shawbury, 301-320 (2014).

[29] Motoyama T., Tsukegi T., Shirai Y., Nishida H., Endo T.: Effects of $\mathrm{MgO}$ catalyst on depolymerization of polyL-lactic acid to L,L-lactide. Polymer Degradation and Stability, 92, 1350-1358 (2007).

https://doi.org/10.1016/j.polymdegradstab.2007.03.014

[30] Fan Y., Nishida H., Moria T., Shirai Y., Endo T.: Thermal degradation of poly(L-lactide): Effect of alkali earth metal oxides for selective L, L-lactide formation. Polymer, 45, 1197-1205 (2004).

https://doi.org/10.1016/j.polymer.2003.12.058

[31] Martino V. P., Jimenez A., Ruseckaite R. A., Averous L.: Structure and properties of clay nano-biocomposites based on poly(lactic acid) plasticized with polyadipates. Polymer Advanced Technologies, 22, 2206-2213 (2011). https://doi.org/10.1002/pat.1747

[32] Wu D., Wu L., Wu L., Zhang M.: Rheology and thermal stability of polylactide/clay nanocomposites. Polymer Degradation and Stability, 91, 3149-3155 (2006). https://doi.org/10.1016/j.polymdegradstab.2006.07.021

[33] Nieddu E., Mazzucco L., Gentile P., Benko T., Balbo V., Mandrile R., Ciardelli G.: Preparation and biodegradation of clay composites of PLA. Reactive and Functional Polymers, 69, 371-379 (2009).

https://doi.org/10.1016/j.reactfunctpolym.2009.03.002

[34] Filippone G., Carroccio S. C., Curcuruto G., Passaglia E., Gambarotti C., Dintcheva N. Tz.: Time-resolved rheology as a tool to monitor the progress of polymer degradation in the melt state - Part II: Thermal and thermo-oxidative degradation of polyamide 11/organo-clay nanocomposites. Polymer, 73, 102-110 (2015). https://doi.org/10.1016/j.polymer.2015.07.042

[35] Passaglia E., Bertoldo M., Ciardelli F., Prevosto D., Lucchesi M.: Evidences of macromolecular chains confinement of ethylene-propylene copolymer in organophilic montmorillonite nanocomposites. European Polymer Journal, 44, 1296-1308 (2008). https://doi.org/10.1016/j.eurpolymj.2008.02.011 